\title{
Transfusion-dependent low-risk myelodysplastic patients receiving deferasirox: Long-term follow-up
}

\author{
SALVATORE IMPROTA ${ }^{1}$, MARIA ROSARIA VILLA ${ }^{1}$, ANTONIO VOLPE $^{2}$, ANGELA LOMBARDI $^{3}$, \\ PAOLA STIUSO $^{3}$, NICOLA CANTORE ${ }^{2}$ and LUCIA MASTRULLO ${ }^{1}$ \\ ${ }^{1}$ Hematology Division, P.O. San Gennaro ASL NA1 Centro, Naples I-80136; \\ ${ }^{2}$ Hematology Division, A.O.R.N. San G. Moscati, Avellino I-83100; ${ }^{3}$ Department of Biochemistry, \\ Biophysics and General Pathology, Second University of Naples, Naples I-80138, Italy
}

Received April 16, 2013; Accepted September 20, 2013

DOI: $10.3892 / \mathrm{ol} .2013 .1617$

\begin{abstract}
Myelodysplastic syndromes (MDSs) are characterized by ineffective hematopoiesis that results in peripheral cytopenias. Anemia is the most common symptom of MDS and the majority of patients become transfusion-dependent with the risk of iron overload, which may lead to cardiac, hepatic and endocrine complications. Deferasirox is an orally available iron chelator administered once-daily in transfusion-dependent patients with various chronic anemias. Its efficacy has been established in controlled clinical trials. In the present study, we describe our experience with 55 consecutive MDS patients [International Prognostic Scoring System risk score of low $(n=32)$ or intermediate-1 $(n=23)$ ] treated with deferasirox in a routine clinical setting following Consensus Guidelines on Iron Chelation Therapy. According to WHO classifications, patients had refractory anemia $(n=30)$, refractory anemia with ringed sideroblasts $(n=16)$, refractory cytopenia with multilineage dysplasia $(n=8)$ or refractory cytopenia with multilineage dysplasia and ringed sideroblasts $(n=1)$. The median monthly transfusion requirement at baseline was 3 units. Patients received a starting dosage of $10 \mathrm{mg} / \mathrm{kg} /$ day, subsequently titrated according to serum ferritin (SF) levels which were measured monthly. Safety assessment included monitoring of liver and renal parameters and recording adverse events (AE) during treatment. At the baseline, the mean \pm SD SF level was $2,362 \pm 172 \mathrm{ng} / \mathrm{ml}$ and after 24 months, the mean \pm SD decrease in $\mathrm{SF}$ was $1,679 \pm 209 \mathrm{ng} / \mathrm{ml}$. Sixteen patients had sustained hematological improvement meeting International Working Group 2006 criteria. One patient became transfusion-independent. No severe AE were reported. In conclusion, deferasirox therapy was effective and safe in reducing transfusional iron
\end{abstract}

Correspondence to: Salvatore Improta, Haematology Division, P.O. San Gennaro ASL NA1 CENTRO, 25 Via San Gennaro dei Poveri, Naples 80136, Italy

E-mail: improta.sal@virgilio.it

Key words: myelodysplastic syndromes, transfusion dependence, iron overload, chelation, deferasirox, erythroid response overload and it reduces transfusion requirement in a subset of patients.

\section{Introduction}

Myelodysplastic syndromes (MDSs) are clonal hematopoietic stem cell disorders characterized by ineffective dysplastic hematopoiesis involving one or more cell lineages, and by peripheral-blood cytopenias with a high risk of progression to acute myeloid leukemia (AML) (1). MDS is most prevalent in white males and the incidence increases markedly with age. The documented disease burden is expected to increase in the near future, due to an aging population and improving awareness of the disease. Approved therapies, including lenalidomide, azacitidine and decitabine are now available for patients who are ineligible for potentially curative hematopoietic stem cell transplantation. These achieve hematological improvement and enhance the quality of life of patients who previously would have received supportive care alone. Thus, the mainstay of treatment for patients with MDS is supportive red blood cell (RBC) transfusions. Repeated transfusions eventually lead to iron overload with an increased risk of associated comorbidity and mortality that is independent of the underlying hematological disease (2). Retrospective studies have revealed that iron toxicity associated with transfusion burden is associated with reduced survival in patients with MDS $(3,4)$. This is particularly problematic in patients with lower risk MDS due to the longer life expectancy.

The most common non-leukemia-related causes of mortality are cardiac failure (51\%) and infections (31\%) (3). Infections may be due to underlying neutropenia or to transfusional iron overload (5). There is growing evidence that adequate iron chelation therapy improves survival in International Prognostic Scoring System (IPSS) lower-risk MDS patients with iron overload and may delay AML transformation (1,6-9). Guidelines recommend that iron overload be managed with chelation therapy (10).

Until recently, desferoxamine and deferiprone were the only drugs available for the treatment of transfusional iron overload. However, neither provides satisfactory chelation therapy for controlling iron toxicity. According to the pharmacokinetic properties of desferoxamine, in order to be effective, 
it must be administered as a slow infusion over the course of 8-12 $\mathrm{h}$ and this must be repeated 5-7 days/week. This regimen is contraindicated in patients with thrombocytopenia and the inconvenience often results in low compliance (11). Deferiprone is not approved for MDS and is not recommended, as it causes neutropenia and agranulocytosis (12).

Deferasirox is a once-daily orally administered iron chelator approved for the treatment of iron overload in patients with transfusion-dependent anemias. It is efficacious and has an acceptable safety profile in adult and pediatric patients with transfusion-dependent thalassemia major and by various other chronic anemias (13). Recent guidelines from the Italian Society of Haematology recommend iron chelation with deferasirox for the treatment of low or intermediate-1 IPSS risk patients with MDS after they have received $\geq 20$ units of packed RBCs (10). The initial dose of $10 \mathrm{mg} / \mathrm{kg}$ may be increased to 20-30 mg/kg based on iron transfusion load, serum ferritin (SF) levels and organ damage due to iron overload. In addition to reducing markers of iron overload, including SF, a number of recently published studies have reported improvements in hematological parameters and transfusion requirements in a portion of patients receiving iron chelation therapy with deferasirox (14-16, reviewed in 17). However, experience outside of clinical trials is lacking. We have investigated the safety and effectiveness of deferasirox therapy in reducing iron overload and transfusion requirements in a non-selected population of polytransfused low-risk MDS patients in a routine clinical setting.

\section{Patients and methods}

Patients affected by low-risk MDS who had been transfusion-dependent for $\geq 1$ year, had SF levels $\geq 2,000 \mathrm{ng} / \mathrm{ml}$ before starting iron chelation therapy and required $\geq 1$ unit of RBCs/month to maintain Hb levels $\geq 8 \mathrm{~g} / \mathrm{dl}$ were enrolled. Thus, these patients were eligible for analysis according to International Working Group 2006 criteria (18). The study was approved by the ethics committee of San Gennaro Hospital (Naples, Italy) and written informed consent was obtained from the patients or the patient's family. Patients were treated at the San Gennaro Hospital (Naples, Italy) or the San G. Moscati Hospital (Avellino, Italy) between June 2006 and June 2012. All patients had low-risk disease, with IPSS scores of low or intermediate-1, and had been receiving only best supportive care.

Patients were treated according to the standard procedures at the enrolling centers. Initially, patients received deferasirox $(10 \mathrm{mg} / \mathrm{kg})$ orally once daily, as recommended by the Italian Society of Haematology, Italian Society of Sperimental Haematology and Italian Group for Bone Marrow Transplantation, Haematopoietic Stem Cells and Cell Therapy guidelines (10). Subsequent dosage adjustments in increments of $10 \mathrm{mg} / \mathrm{kg} /$ day were based on efficacy in terms of reduction in SF and safety parameters. The maximum dosage was $30 \mathrm{mg} / \mathrm{kg} /$ day (Table I).

Patients had an initial visit at baseline and follow-up visits at $\sim 2$-week intervals thereafter. At each visit, the deferasirox dosage, number of blood transfusions received, and changes in concomitant medications and iron intake were recorded. Hematological response was determined
Table I. Deferasirox dosage for all 55 consecutive patients.

\begin{tabular}{lc}
\hline Dosage & $\begin{array}{c}\text { Patients } \\
(\mathrm{n}=55)\end{array}$ \\
\hline $\begin{array}{l}\text { Starting dose }, \mathrm{mg} / \mathrm{kg} / \text { day } \\
\text { Median daily deferasirox dose }\end{array}$ & 10 \\
over the course of the study, mgkg/day (range) & $23(10-30)$ \\
Dose adjustments for starting dose ${ }^{\mathrm{a}}, \mathrm{n}(\%)$ & \\
Unchanged & $10(18)$ \\
Increased & $45(82)$ \\
Dose adjustments during treatment ${ }^{\mathrm{b}}, \mathrm{n}(\%)$ & \\
Unchanged & $38(69)$ \\
Increased & $11(20)$ \\
Reduced & $6(11)$
\end{tabular}

${ }^{\mathrm{a} B a s e l i n e ~ c o m p a r e d ~ w i t h ~ f i n a l ~ v i s i t ; ~}{ }^{\mathrm{b}}$ second month compared with final visit.

according to International Working Group 2006 criteria (18). Laboratory examinations for renal function (serum creatinine, 24-h creatinine excretion and creatinine clearance using the Cockcroft-Gault and Modification of Diet in Renal Disease formulae) and hepatic function (serum transaminases, bilirubin, alkaline phosphatase and $\gamma$-glutamyl transpeptidase) were performed at baseline and then weekly for the first month of treatment, monthly for the next 5 months and bimonthly thereafter. Examination of the ocular fundus and audiometric tests were performed at baseline and then every 6 months.

\section{Results}

We enrolled 55 consecutive unselected patients affected by low-risk MDS who had been transfusion-dependent for $\geq 1$ year. All patients (33 males and 22 females; median age, 70 years) had SF levels $\geq 2,000 \mathrm{ng} / \mathrm{ml}$ before starting iron chelation and required $\geq 1$ unit of $\mathrm{RBCs} /$ month to maintain $\mathrm{Hb}$ levels at $\geq 8 \mathrm{~g} / \mathrm{dl}$ (Table II). Four of the 55 patients had received prior chelation therapy with desferoxamine, which had been discontinued due to renal toxicity. The median transfusion requirement before starting treatment was 3 units/month.

To date, all patients had $>24$ months of follow-up. Mean iron intake was $0.31 \mathrm{mg} / \mathrm{kg} / \mathrm{day}$ at the baseline and $0.26 \mathrm{mg} / \mathrm{kg} /$ day after 24 months of therapy. All patients exhibited significant decreases in iron overload, as measured by SF, which were maintained after 2 years of therapy (mean absolute decrease in SF from baseline, 1,679 $\pm 209 \mathrm{ng} / \mathrm{ml}$; range 1,250-2,100 ng/ml), corresponding to a mean reduction of $71 \%$. The rate of decrease in SF levels was relatively constant over the 24-month observation period (Fig. 1).

A sustained reduction in transfusion requirement was recorded in 16 of the 55 patients. Transfusion requirements were reduced by at least one transfusion per month after 6 months of therapy in all 16 patients who responded and were followed in all cases by further improvements at 24 months, meeting 2006 International Working Group criteria for hematological response (Table III). All 16 patients had erythroid responses, including one in a patient with multilinear dysplasia. There were no significant increases in neutrophil or platelet counts. 
Table II. Demographic and clinical characteristics of 55 patients at diagnosis.

\begin{tabular}{lc}
\hline Characteristics & Patients \\
\hline Male, n (\%) & $33(60)$ \\
Female, n (\%) & $22(40)$ \\
Median age, years (range, IQR) & $70(58-79,9)$ \\
WHO classification, $\mathrm{n}$ & \\
RA & 30 \\
RARS & 16 \\
RCMD & 8 \\
RCMD-RS & \\
Transfusion requirement, unit/month, & $2.9 \pm 0.95$ \\
mean \pm SD & 32 \\
Prognosis (IPSS), $\mathrm{n}$ & 23 \\
Low & \\
Intermediate-1 & 41 \\
Prognosis (WPSS), $\mathrm{n}$ & 14 \\
Low & $2362 \pm 172$ \\
Intermediate-1 & $7.3 \pm 0.17$ \\
Serum ferritin, ng/ml, mean \pm SD & \\
Hb, g/dl, mean \pm SD & \\
\hline
\end{tabular}

IQR, interquartile range; RA, refractory anemia; RARS, refractory anemia with ringed sideroblasts; RCMD, refractory cytopenia with multilineage dysplasia; RCMD-RS, refractory cytopenia with multilineage dysplasia and ringed sideroblasts; IPSS, International Prognostic Scoring System; WPSS, World Health Organisation Classification-Based Prognostic Scoring System; $\mathrm{Hb}$, hemoglobin.

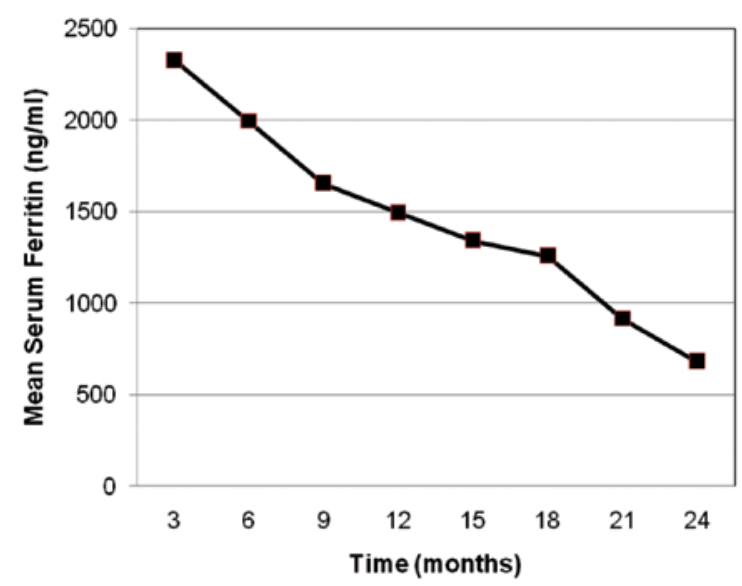

Figure 1. Mean serum ferritin levels $(\mathrm{ng} / \mathrm{ml})$ for 55 patients over the course of 24 months of treatment with deferasirox.

The mean monthly transfusion requirement at baseline was 3.25 units for the 16 patients who responded compared with 2.75 units among patients who did not have a hematological response; mean age was 69 years in the two groups. Among the patients who responded, less than one-fourth $(3 / 16)$ were female, compared with approximately half of non-responders $(19 / 39)$.
At baseline, these 16 patients had a mean transfusion requirement of 3.3 units/month, which decreased to 2.0 units/month after 6 months of treatment and to 1.1 units/month after 24 months. These values were relatively unchanged in the remaining patients, who required a mean 2.8, 2.7 and 2.8 units/month at baseline, 6 and 12 months, respectively. One patient became transfusion-independent after 13 months of iron chelation therapy. The patient was transfusion-free (SF, $800 \mathrm{ng} / \mathrm{ml}$ ) with a hemoglobin level of $\sim 8.8 \mathrm{~g} / \mathrm{dl}$ in December 2012, 30 months after starting iron chelation therapy.

With regard to the onset of improvements in erythropoiesis, in 7/16 patients this occurred by 6 months, while all 16 patients had responses meeting International Working Group 2006 criteria after 12 months of treatment. Erythroid responses were observed when SF levels had been reduced by $\sim 40 \%$ compared with baseline. There was a persistent reduction of transfusion requirements in approximately one third of patients.

Adverse events (AE) were documented in 34 patients $(61.8 \%)$. All AEs were mild in severity (grade 1-2) and did not require discontinuation of therapy. The most common drug-related AEs were diarrhea, nausea, rash and headache (Table IV). There were no clinically significant alterations of renal or hepatic function. Similarly, optical and audiometric tests were normal.

\section{Discussion}

Iron overload in patients with transfusion-dependent MDS is an important clinical problem, as secondary hemosiderosis may lead to organ failure in patients with a long life expectancy. Moreover, several studies have shown that the survival of patients with MDS is affected by transfusion dependence, which is a poor independent prognostic factor (19). Iron overload also has a negative impact on the success of stem cell transplantation (20).

In order to prevent iron toxicity, current guidelines indicate that iron chelation therapy should be considered in patients with SF levels of $1,000 \mathrm{ng} / \mathrm{ml}$ and who require 2 units $\mathrm{RBC}$ transfusions per month for $\geq 1$ year.

Our findings are in agreement with results of the Evaluation of Patients' Iron Chelation with Exjade ${ }^{\circledR}$ (EPIC) study, the largest prospective evaluation of an iron chelation therapy conducted to date, which confirmed that deferasirox is an efficacious and generally well-tolerated treatment for iron overload in patients with transfusion-dependent disorders, including $\beta$-thalassemia and MDS (19). Our results, based on over 24 months of follow-up in non-selected MDS patients treated in a routine clinical setting, confirm the effectiveness and safety of deferasirox therapy in reducing the iron overload in polytransfused MDS patients.

We also identified a subset of 16 patients who had a reduction in transfusion requirement meeting International Working Group criteria for hematological response. This is in agreement with previous observations of hematological improvement with chelation therapy (reviewed in 17).

Moreover, a post hoc analysis of a subgroup of 341 patients with myelodysplastic syndromes enrolled in the EPIC study also identified hematological responses to deferasirox in a 
Table III. Characteristics of 16 patients meeting 2006 International Working Group criteria for haematological improvement while receiving deferasirox.

\begin{tabular}{|c|c|c|c|c|c|c|c|c|c|c|c|}
\hline \multirow[b]{2}{*}{ Gender } & \multirow{2}{*}{$\begin{array}{l}\text { Age } \\
\text { (years) }\end{array}$} & \multirow{2}{*}{$\begin{array}{l}\text { Histological } \\
\text { classification }\end{array}$} & \multirow{2}{*}{$\begin{array}{l}\text { Prognosis } \\
\text { (IPSS) }\end{array}$} & \multicolumn{3}{|c|}{$\begin{array}{l}\text { Transfusion support } \\
\text { (units/month) }\end{array}$} & \multicolumn{2}{|c|}{$\begin{array}{l}\text { Serum ferritin } \\
\qquad(\mathrm{ng} / \mathrm{ml})\end{array}$} & \multicolumn{3}{|c|}{$\begin{array}{l}\text { Haemoglobin } \\
(\mathrm{g} / \mathrm{dl})\end{array}$} \\
\hline & & & & Baseline & 6 months & 24 months & Baseline & 24 months & Baseline & 24 months & Change \\
\hline M & 72 & RA & INT-1 & 3 & 2 & 1 & 2400 & 850 & 7.0 & 8.6 & 1.6 \\
\hline M & 72 & RARS & INT-1 & 3 & 2 & 1 & 2420 & 850 & 7.3 & 8.8 & 1.5 \\
\hline M & 72 & RA & INT-1 & 3 & 2 & 1 & 2440 & 850 & 7.3 & 8.8 & 1.5 \\
\hline M & 60 & RA & LOW & 3 & 2 & 1 & 2350 & 750 & 7.3 & 8.9 & 1.6 \\
\hline M & 73 & RCMD & INT-1 & 3 & 2 & 1 & 2450 & 850 & 7.3 & 8.8 & 1.5 \\
\hline M & 60 & RA & LOW & 3 & 2 & 1 & 2350 & 750 & 7.4 & 9.0 & 1.6 \\
\hline $\mathrm{F}$ & 72 & RA & LOW & 3 & 2 & 1 & 2100 & 450 & 7.3 & 8.8 & 1.5 \\
\hline M & 60 & RA & LOW & 3 & 2 & 1 & 2450 & 750 & 7.2 & 8.8 & 1.6 \\
\hline M & 67 & RARS & LOW & 4 & 3 & 2 & 2540 & 700 & 7.0 & 8.6 & 1.6 \\
\hline M & 67 & RARS & LOW & 4 & 3 & 2 & 2540 & 700 & 7.0 & 8.6 & 1.6 \\
\hline M & 67 & RARS & LOW & 4 & 3 & 2 & 2540 & 700 & 7.0 & 8.6 & 1.6 \\
\hline M & 74 & RA & LOW & 3 & 1 & 1 & 2350 & 800 & 7.2 & 8.7 & 1.5 \\
\hline $\mathrm{F}$ & 74 & RA & LOW & 3 & 1 & 1 & 2350 & 800 & 7.4 & 9.1 & 1.7 \\
\hline M & 74 & RARS & INT-1 & 3 & 1 & 1 & 2350 & 800 & 7.0 & 8.6 & 1.6 \\
\hline $\mathrm{F}$ & 67 & RA & LOW & 4 & 3 & 1 & 2340 & 700 & 7.0 & 8.5 & 1.5 \\
\hline M & 74 & RA & LOW & 3 & 1 & 0 & 2350 & 800 & 7.0 & 8.8 & 1.8 \\
\hline
\end{tabular}

IPSS, International Prognostic Scoring System; RA, refractory anemia; RARS, refractory anemia with ringed sideroblasts; RCMD, refractory cytopenia with multilineage dysplasia; INT-1, intermediate-1.

Table IV. Adverse events recorded in all 55 patients through 24 months of therapy with deferasirox. All adverse events were grade $1-2$.

\begin{tabular}{lcr}
\hline Adverse event & Events, $\mathrm{n}$ & Patients, $\mathrm{n}(\%)$ \\
\hline Diarrhea & 20 & $15(27.0)$ \\
Nausea & 11 & $10(18.0)$ \\
Rash & 8 & $8(14.5)$ \\
Headache & 8 & $8(14.5)$ \\
\hline
\end{tabular}

cohort of iron-overloaded patients (15). In this study, erythroid hematopoietic responses, according to International Working Group 2006 criteria, were observed in 53 of 247 patients eligible for analysis $(21.5 \%)$ and there was a trend toward greater reductions in SF in patients with hematological responses. The erythroid response rate using the same criteria was similar in our study $(29 \%, 16 / 55)$.

The results of the multicenter prospective Gimema trial of 152 consecutive patients (median age, 72 years) with low or intermediate-1 risk MDS were reported (16). After one year of deferasirox treatment, 22 patients had achieved transfusion independence, defined as no transfusion requirements for three consecutive months. The probability of acquiring transfusion independence after one year was 19.7\% (95\% CI, 19.4-20). While a similar percentage of our patients achieved a hematological response, only one patient achieved complete transfusion independence.
List et al (14) enrolled 176 patients with low or intermediate-1-risk MDS and SF levels $>1,000 \mathrm{mg} / 1$ to receive treatment with deferasirox. The median reduction in SF was $36.7 \%$ in the 49 patients $(28 \%)$ who completed 24 months of treatment. This is considerably less than our finding of a median reduction in SF of $70.2 \%$ at 24 months. Additionally, the rate of hematological erythroid responses defined by International Working Group 2006 criteria was lower in this study $(30 \%, 51 / 176)$, compared with that in our patients $(29 \%$, 16/55).

However, the mechanism underlying the hematological response is not known. Reduction of oxidative stress caused by excess free iron in bone marrow has been implicated in bone marrow toxicity (21). Reduction of labile iron with chelation therapy has been proposed as the mechanism underlying hematological responses (17). Ghoti et al (22) measured labile iron (the redox-active form) and reactive oxygen species in blood cells from patients who had received deferasirox therapy for 3 months. The authors identified significant reductions in reactive oxygen species and lipid peroxidation, as well as an increase in the antioxidant, reduced glutathione.

A direct effect of deferasirox on hematopoiesis through the nuclear factor- $\kappa \mathrm{B}(\mathrm{NF}-\kappa \mathrm{B})$ pathway has been proposed, based on in vitro experiments showing strong, iron-independent inhibition of $\mathrm{NF}-\kappa \mathrm{B}$ by deferasirox, but not other chelators (23). However, there is also limited evidence of hematological improvement in patients with MDS treated with desferoxamine (24), which argues against a direct role for deferasirox. Gattermann et al (15) found that, while treatment with deferasirox reduced labile iron to $<0.4 \mu \mathrm{mol} / 1$, there was no difference 
between hematological responders and non-responders. If removal of iron is labile, since it is the underlying mechanism of the hematological response, one may expect to see a difference between these groups.

The timing of hematological responses may give an indication of the mechanism. Seven of the patients in the present study had responded after 6 months of treatment and all 16 patients responded after 12 months. Patients appeared to respond when they had reached an $\sim 40 \%$ reduction in SF. In the 3-year study by List et al (14), the median time to any type of hematological response was also $\sim 6$ months.

Further studies are warranted to define the role of deferasirox in reducing the blood transfusion request in a subset of patients affected by MDS that is refractory to other conventional therapies.

\section{Acknowledgements}

The authors would like to thank all the patients and investigators who took part in the study.

\section{References}

1. Neukirchen J, Fox F, Kündgen A, Nachtkamp K, Strupp C, Haas R, Germing U and Gattermann N: Improved survival in MDS patients receiving iron chelation therapy - a matched pair analysis of 188 patients from the Düsseldorf MDS registry. Leuk Res 36: 1067-1070, 2012.

2. Dreyfus F: The deleterious effects of iron overload in patients with myelodysplastic syndromes. Blood Rev 22 (Suppl 2): S29-S34, 2008.

3. Malcovati L, Porta MG, Pascutto C, Invernizzi R, Boni M, Travaglino E, Passamonti F, Arcaini L, Maffioli M, Bernasconi P, et al: Prognostic factors and life expectancy in myelodysplastic syndromes classified according to WHO criteria: a basis for clinical decision making. J Clin Oncol 23: 7594-7603, 2005.

4. Delea TE, Hagiwara M and Phatak PD: Retrospective study of the association between transfusion frequency and potential complications of iron overload in patients with myelodysplastic syndrome and other acquired hematopoietic disorders. Curr Med Res Opin 25: 139-147, 2009.

5. Toma A, Fenaux P, Dreyfus F and Cordonnier C: Infections in myelodysplastic syndromes. Haematologica 97: 1459-1470, 2012.

6. Rose C, Brechignac S, Vassilief D, et al: Does iron chelation therapy improve survival in regularly transfused lower risk MDS patients? A multicenter study by the GFM (Groupe Francophone des Myélodysplasies). Leuk Res 34: 864-870, 2010.

7. Komrokji RS, Al Ali NH, Padron E, Lancet JE and List AF: Impact of iron chelation therapy on overall survival and AML transformation in lower risk MDS patients treated at the Moffitt Cancer Center. Blood (ASH Annual Meeting Abstracts) 118: 2776, 2011.

8. Lyons RM, Marek BJ, Paley C, et al: Relationship between chelation and clinical outcomes in 600 lower-risk MDS ratients: registry analysis at 36 months. Blood (ASH Annual Meeting Abstracts) 120: 3800, 2012

9. de Swart L, Smith A, Fenaux P, et al: Early mortality in 1000 newly diagnosed MDS patients with low- and intermediate-1 risk MDS in the European Leukemianet MDS (EUMDS) registry. Blood (ASH Annual Meeting Abstracts) 120: 3830, 2012.
10. Santini V, Alessandrino PE, Angelucci E, Barosi G, Billio A, Di Maio M, et al: Clinical management of myelodysplastic syndromes: update of SIE, SIES, GITMO practice guidelines. Leuk Res 34: 1576-1588, 2010.

11. Arboretti R, Tognoni G and Alberti D: Italian Colaborative Group on Thalassarmia Pharmacosurveillance and quality of care of thalassaemic patients. A large scale epidemiological survey. Eur J Clin Pharmacol 56: 915-922, 2001.

12. Cappellini MD and Piga A: Current status in iron chelation in hemoglobinopathies. Curr Mol Med 8: 663-674, 2008.

13. Galanello R, Campus S and Origa R: Deferasirox: pharmacokinetics and clinical experience. Expert Opin Drug Metab Toxicol 8: 123-134, 2012.

14. List AF, Baer MR, Steensma DP, Raza A, Esposito J, Martinez-Lopez N, et al: Deferasirox reduces serum ferritin and labile plasma iron in RBC transfusion dependent patients with myelodysplastic syndrome. J Clin Oncol 30: 2134-2139, 2012.

15. Gattermann N, Finelli C, Della Porta M, et al: Hematologic responses to deferasirox therapy in transfusion-dependent patients with myelodysplastic syndromes. Haematologica 97: 1364-1371, 2012

16. Angelucci E, Santini V, Di Tucci AA, et al: Deferasirox chelation therapy in transfusion dependent MDS patients. Final report from the GIMEMA MDS0306 prospective trial. Blood (ASH Annual Meeting Abstracts) 120: 425, 2012.

17. Guariglia R, Martorelli MC, Villani O, Pietrantuono G, Mansueto G, D'Auria F, et al: Positive effects on hematopoiesis in patients with myelodysplastic syndrome receiving deferasirox as oral iron chelation therapy: a brief review. Leuk Res 35: 566-570, 2011.

18. Cheson BD, Greenberg PL, Bennett JM, et al: Clinical application and proposal for modification of the International Working Group (IWG) response criteria in myelodysplasia. Blood 108: 419-425, 2006

19. Gattermann N, Finelli C, Della Porta M, et al: Deferasirox in iron-overloaded patients with transfusion-dependent myelodysplastic syndromes: Results from the large 1-year EPIC study. Leuk Res 34: 1143-1150, 2010.

20. Armand P, Kim HT, Cutler CS, Ho VT, Koreth J, Alyea EP, Soiffer RJ and Antin JH: Prognostic impact of elevated pretransplantation serum ferritin in patients undergoing myeloablative stem cell transplantation. Blood 109: 4586-4588, 2007.

21. Yahata T, Takanashi T, Muguruma Y, Ibrahim AA, Matsuzawa H, Uno T, Sheng Y, Onizuka M, Ito M, Kato S and Ando K: Accumulation of oxidative DNA damage restricts the self-renewal capacity of human hematopoietic stem cells. Blood 118: 2941-2950, 2011.

22. Ghoti H, Fibach E, Merkel D, Perez-Avraham G, Grisariu S and Rachmilewitz EA: Changes in parameters of oxidative stress and free iron biomarkers during treatment with deferasirox in iron-overloaded patients with myelodysplastic syndromes. Haematologica 95: 1433-1434, 2010.

23. Messa E, Carturan S, Maffé C, Pautasso M, Bracco E, Roetto A, et al: Deferasirox is a powerful NF-kappaB inhibitor in myelodysplastic cells and in leukemia cell lines acting independently from cell iron deprivation by chelation and reactive oxygen species scavenging. Haematologica 95: 1308-1316, 2010.

24. Jensen PD, Jensen IM and Ellegaard J: Desferoxamine treatment reduces blood transfusion requirements in patients with myelodysplastic syndrome. Br J Haematol 80: 121-124, 1992. 